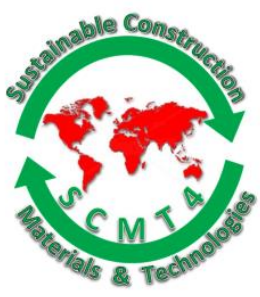

\title{
Assessment of the Behavior of Steel-Fiber Reinforced Concrete Produced with Different Ratios of Fine-to-Coarse Aggregate
}

\author{
Merve AÇIKGENÇ ULAŞ*1, Kürşat Esat ALYAMAÇa and Zülfü Çınar ULUCAN²b \\ ${ }^{1}$ Architecture Department, Firat University, TURKEY, Assistant Professor, Email: \\ <merveacikgenc@firat.edu.tr>. \\ ${ }^{2}$ Civil Engineering Department, Firat University, TURKEY, \\ ${ }^{2 a}$ Assistant Professor, Email: <kealyamac@firat.edu.tr>. ${ }^{2 b}$ Professor, Email: <zculucan@firat.edu.tr>.
}

\begin{abstract}
Aggregate is an important ingredient of concrete that affects both fresh and hardened properties of concrete. The properties of concrete can be enhanced or worsened by changing properties of aggregate, especially particle size distribution of aggregate. However, in the literature, the effects of particle size distribution of aggregate on the properties of concrete have been neglected for particularly Steel-Fiber Reinforced Concrete (SFRC) although packing is a very important aspect for SFRC quality. Thus, this study investigates the effects of changing particle size distribution and maximum size $\left(D_{\max }\right)$ of aggregate on the workability and mechanical properties of SFRC. With this aim, three gradations and two $D_{\max }$ were used to produce SFRC mixtures with constant cement dosages and water/cement ratios. Totally, nine different concrete series were tested. To observe the properties of fresh concrete, Slump and $\mathrm{Ve}-\mathrm{Be}$ tests were performed. The compressive, splitting tensile and flexural strengths of concretes were also evaluated, and the toughness of the SFRC specimens was calculated. Based on the test results, it can be concluded that the ratio of fine-to-coarse aggregate, the void content between the aggregate particles and $D_{\max }$ have remarkable effects on the properties of both fresh and hardened SFRC. In addition, the toughness of the SFRC specimens which has constant cement dosage, and water/cement ratios were influenced by those aspects of the aggregates.
\end{abstract}

\section{INTRODUCTION}

Approximately $75 \%$ of the concrete volume is occupied by aggregates and the aggregate properties greatly influence the performance and quality of the concrete. Lots of parameters related to the aggregates, like chemical and mineral compositions, shape, roughness, degree of weathering, specific gravity, hardness, strength, physical and chemical stability and pore structure have effects on the properties of the concrete. Moreover, particle size distribution (grading/gradation) and the maximum aggregate size $\left(D_{\max }\right)$ significantly influence the fresh and hardened properties of the concrete [Mehta and Monteiro 2006; Meddah et al. 2010]. Grading is the distribution of various sized aggregate particles. The $D_{\max }$ can vary, but in aggregate composition, particles of different dimensions will be existed. The grading of a given sample means that an aggregate composition is too fine, too coarse or gap-graded aggregate (lacing in a particular aggregate size). In addition, the fineness modulus is used to characterize and evaluate a grading curve with one single parameter. In other words, the higher fineness modulus is, the coarser the aggregate proportion 
is, while the lower the fineness modulus is, the finer the aggregate proportion is. Aggregate gradations also reflect the surface area of aggregates that needs to be covered with cement paste and water. Thus, to wet all of the particles, the surface area of the aggregates determines the required amount of water. The higher the aggregates surface area is, the lower amounts of cement paste are needed to fill the voids between the particles $\left(V_{\text {void }}\right)$. Because water need is determined by the surface area of fine particles, the fresh concrete mixture might be unworkable. On the other hand, increasing the water amount can lead to decreased mechanical strength. It is also assumed that packing coarser particles into a given volume of concrete can result in higher mechanical strength of concrete [Mehta and Monteiro 2006; Neville 1991; Alexander and Mindess 2005]. In the literature, it was proved that changing the amount of coarse aggregates influences the compressive strength of the concrete. In addition, there is an optimal content of coarse aggregate to enhance the compressive strength with a given w/c ratio. Increasing the coarse aggregate content beyond that optimal value further reduced the compressive strength. In addition, decreasing $D_{\max }$ decreases compressive strength and splitting tensile strength [Cetin and Carrasquillo 1998; Ozbay 2010; Tumidajski and Gong 2006; Meddah et al. 2010].

Steel fiber reinforced concrete (SFRC) is described as concrete containing hydraulic cement, water, fine and coarse aggregates with discontinuous steel fibers. The steel fibers are used to enhance the mechanical concrete properties and eliminate the brittleness of concrete. They can be produced of various shapes and sizes [Mehta and Monteiro 2006; Brandt 2008; ACI 544.1R 2005]. By means of delaying occurring of tension cracks or blocking the propagation of cracks, steel fibers enhance the ductility of the concrete [Mehta and Monteiro 2006]. Thus, the tensile strength and toughness can be improved by adding steel fibers to plain concrete [Banthia and Sappakittipakorn 2007; Nataraja et al. 1999; Gopalaratnam and Gettu 1995; Tadepalli et al. 2013]. As including a conventional plane concrete matrix between the steel fibers, similar to conventional concrete, the workability and mechanical properties of SFRC are influenced by the cement content, the water/cement ratio and the aggregate features [Banthia 1990]. It is known that $D_{\max }$ and amount of fine or coarse aggregate has an influence on the properties of SFRC. Chenkui and Guofan [1995] investigated the mechanical properties of SFRC with two different $D_{\max }$ and four different fine-to-coarse aggregate ratios. They concluded that all strength values showed improvements with the addition of steel fibers and increasing the $D_{\max }$. In another study, different fiber types are used to produce SFRC specimens with different aggregate groups. Although the compressive strength of the SFRC was affected slightly, the bond strength of the steel fibers was improved with increasing fine-to-coarse aggregate ratio [Kim et al. 2012]. Thus, the proportion of the aggregates has effects on the properties of both conventional concrete and the SFRC. The ACI committee 544 suggests aggregate gradations for trial mixtures and $D_{\max }$ values. Compared SFRC to conventional concrete, workability decreases with fiber content. Some SFRC mixtures are suggested to characterize as having higher cement and higher fine aggregate contents to maintain a good workability. Therefore, increasing the steel fiber volume fraction $\left(V_{f}\right)$ and $D_{\max }$ might also increase the affection for clustering of the steel fibers [ACI 544.1R 2005]. Most of the SFRC researches focus on the effects of fiber volume fraction and fiber type on the properties of SFRC. Some of these studies research cement dosage and water/cement ratio [Tadepalli et al. 2013; Banthia 1990; Neves and Fernandes de Almeida 2005]. But the influences of aggregate parameters on the properties of SFRC are generally not appreciated enough. Considering SFRC includes conventional plain concrete as a matrix between the steel fibers, we carry out the effects of different aggregate gradations on the workability and mechanical properties of SFRC rather than fiber volume fraction and fiber type. Keeping the fineness modulus constant, these gradations vary in terms of maximum aggregate size $\left(D_{\max }\right)$ and fine-to-coarse aggregate ratio $(F / C)$.

\section{EXPERIMENTAL PROGRAM}

Material properties. All SFRC mixtures had constant cement dosage and water/cement (W/C) ratios. CEM I 42.5 N type Portland cement (PC) complying with the requirements of TS EN 197-1 [2005] Standards was used. To maintain the workability without adding extra water for the fresh SFRC mixtures, a polycarboxylate-based super plasticizer (SP) admixture was used. The specific gravity of the admixture was $1.1 \mathrm{~g} / \mathrm{cm}^{3}$. 
Crushed calcareous aggregates were used in all mixtures. The specific gravity of coarse $(31.5 \sim 8 \mathrm{~mm})$, medium $(8 \sim 2 \mathrm{~mm})$ and fine (1mm filler) aggregates were respectively $2.68,2.60$ and $2.58 \mathrm{~g} / \mathrm{cm}^{3}$ and their water absorption rates were also respectively $0.3,2.2$ and $3 \%$. According to the basic sieve series, crushed calcareous aggregates were sieved and divided as recommended in the TS 706 EN 12620 [2009] standard. Aggregates were added to concrete mixtures with the percentages of designed gradations. 6 types of gradations were calculated with two different maximum aggregate sizes $\left(D_{\max }\right)$.

Normal strength, hooked end-type steel fibers added to the SFRC mixtures. The tensile strength of the steel fibers was $1250 \mathrm{MPa}$ and the modulus of elasticity was $200 \mathrm{GPa}$. The fiber length $(l)$ and the fiber diameter (d) were respectively $60 \mathrm{~mm}$ and $0.75 \mathrm{~mm}$ and the aspect ratio $(/ / d)$ of the fibers was 80 .

Mixture proportions. Constant cement dosage, W/C ratio and the amount of SP were used to produce all of the SFRC mixtures. The volume fractions $\left(V_{f}\right)$ of the steel fiber were $0 \%$ (reference) and $1 \%$ for the 9 different SFRC mixes. Table 1 gives the mixture proportions. The aggregate contents are given according to sieve sizes (Table 1). For example, $\frac{\mathbf{1 6}}{\mathbf{8}}$ means that the aggregates passed through a $16 \mathrm{~mm}$ square mesh sieve and were retained on an $8 \mathrm{~mm}$ square mesh sieve. For the mixture codes, the numbers 16 and 31.5 (32) refer to the $D_{\max }$ values of the mixtures. $B^{\prime \prime}, B$ and $B^{\prime}$ sign define the grading curves. The mixture code with $\mathrm{R}$ means that these mixtures are referred to as the reference series (Table 1).

Table 1. SFRC Mixture Proportions

\begin{tabular}{|c|c|c|c|c|c|c|c|c|c|c|c|c|c|}
\hline \multicolumn{14}{|c|}{ Mixture Proportions $\left(\mathrm{kg} / \mathrm{m}^{3}\right)$} \\
\hline \multirow{3}{*}{$\begin{array}{l}\text { Mix } \\
\text { Code }\end{array}$} & \multirow[t]{3}{*}{$\mathrm{PC}$} & \multirow[t]{3}{*}{$\mathrm{W} / \mathrm{C}$} & \multirow{3}{*}{$\begin{array}{l}\text { Steel } \\
\text { Fiber }\end{array}$} & \multirow[t]{3}{*}{ SP } & \multicolumn{9}{|c|}{ Aggregates divided by sieve sizes $(\mathrm{mm})$} \\
\hline & & & & & 32 & 16 & 8 & 4 & 2 & 1 & 0.5 & 0.25 & $<0.125$ \\
\hline & & & & & $\overline{16}$ & 8 & $\overline{4}$ & $\overline{2}$ & $\overline{1}$ & $\overline{0.5}$ & $\overline{0.25}$ & $\overline{0.125}$ & \\
\hline R-B"16 & 350 & 0.5 & 0 & 7.0 & 0 & 216 & 365 & 374 & 18 & 272 & 245 & 181 & 154 \\
\hline B"16 & 350 & 0.5 & 78.5 & 7.0 & 0 & 216 & 365 & 374 & 18 & 272 & 245 & 181 & 154 \\
\hline B"32 & 350 & 0.5 & 78.5 & 7.0 & 216 & 621 & 265 & 18 & 100 & 172 & 154 & 181 & 118 \\
\hline R-B16 & 350 & 0.5 & 0 & 7.0 & 0 & 151 & 310 & 347 & 310 & 235 & 199 & 145 & 127 \\
\hline B16 & 350 & 0.5 & 78.5 & 7.0 & 0 & 151 & 310 & 347 & 310 & 235 & 199 & 145 & 127 \\
\hline B32 & 350 & 0.5 & 78.5 & 7.0 & 151 & 546 & 256 & 219 & 164 & 145 & 127 & 145 & 91 \\
\hline R-B'16 & 350 & 0.5 & 0 & 7.0 & 0 & 85 & 256 & 319 & 602 & 208 & 154 & 118 & 82 \\
\hline $\mathrm{B}^{\prime} 16$ & 350 & 0.5 & 78.5 & 7.0 & 0 & 85 & 256 & 319 & 602 & 208 & 154 & 118 & 82 \\
\hline $\mathrm{B}^{\prime} 32$ & 350 & 0.5 & 78.5 & 7.0 & 85 & 480 & 246 & 493 & 146 & 118 & 100 & 100 & 72 \\
\hline
\end{tabular}

Keeping the volumes of the aggregates and the volume of cement paste constant for all of the mixtures, there are 6 different compositions of aggregates used in this study. The aggregate compositions were prepared for the grading curves, which are shown in figure 1. In this study, three different grading curves with two different $D_{\max }$ values were used (figure 1). $B$ gradings is one of the recommending limit gradings of TS 802 [2009] standard. For each $D_{\max }$ values, the $B^{\prime \prime}$ and $B^{\prime}$ gradings had the same fineness modulus as the $\mathrm{B}$ gradings while the fine-to-coarse aggregate ratios were varied (Table 2). According to TS 706 EN 12620 [2009] standard, coarse aggregates are the particles larger than $4 \mathrm{~mm}$ and fine aggregates are the particles smaller than $4 \mathrm{~mm}$. Thus, the fine aggregate percentages and fine-to-coarse aggregate ratios can be calculated by the mass of each aggregate gradations (Table 2).

Another important parameter, the void contents between the aggregate particles are also presented in Table 2. To measure the void content, a container of known volume was used and the aggregate was placed in the container. Weight of the aggregate was then measured. The void content of the aggregate particles $\left(V_{\text {void }}\right)$ was obtained using Eq. (1) following, 


$$
V_{\text {void }}=\left[1-\frac{V_{a}}{V_{c}}\right] \times 100
$$

where $V_{\text {void }}$ is the void content of the aggregate particles $(\%), V_{a}$ is the volume of the aggregates $\left(\mathrm{dm}^{3}\right)$ and $V_{c}$ is the volume of the container $\left(\mathrm{dm}^{3}\right)$. As shown in Table 2, for each $D_{\max }$ value, the gradations $B^{\prime \prime}, B$ and $B^{\prime}$ have the same fineness modulus. In addition, larger $D_{\max }$ values make the gradations coarser. As mentioned before, the volume of cement paste is constant for all mixtures which are needed to fill between the aggregate particles. Thus, variable void content between the aggregate particles might result in incomplete filling and cause unfilled void volume in concrete, which can adversely affect the quality of the concrete.
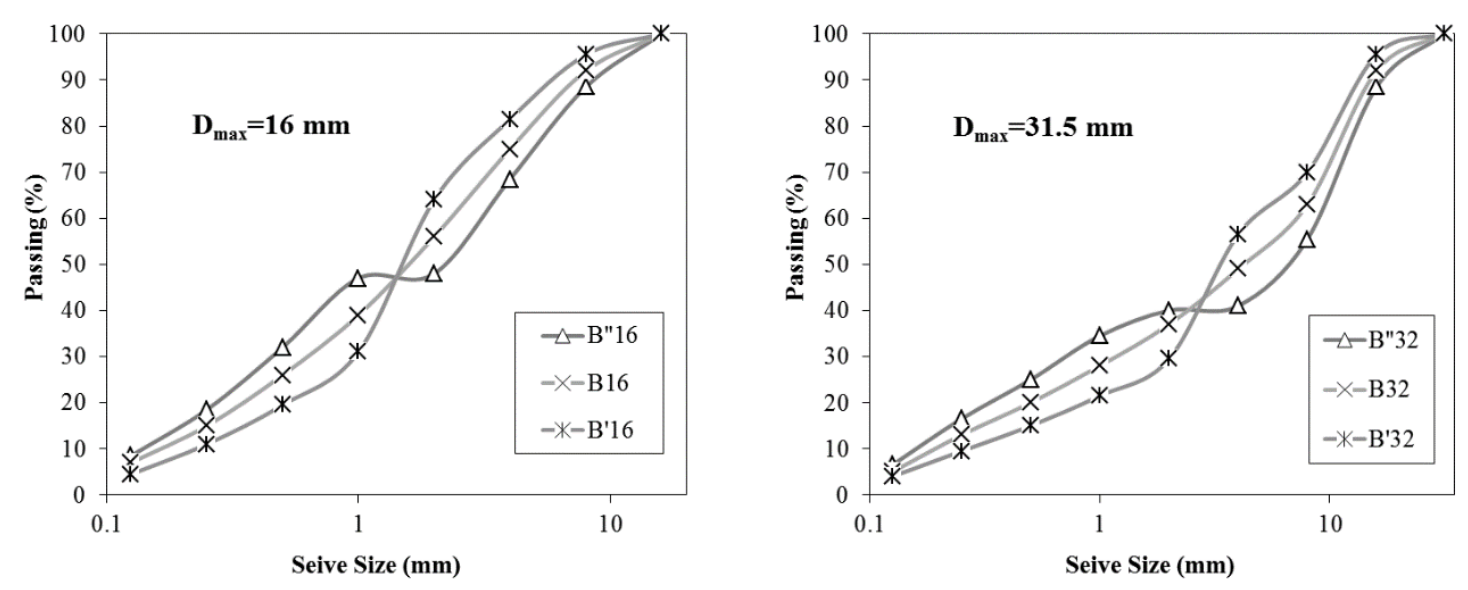

Figure 1. Gradation Curves of Aggregates

Table 2. Calculated Parameters of Aggregate Gradations

\begin{tabular}{|c|c|c|c|c|c|}
\hline Code & $\begin{array}{c}D_{\max } \\
(\mathrm{mm})\end{array}$ & $\begin{array}{c}\text { Fineness } \\
\text { Modulus } \\
(k)\end{array}$ & $\begin{array}{c}\text { Fine } \\
\text { Aggregate }(\%)\end{array}$ & $\begin{array}{c}V_{\text {void }} \\
(\%)\end{array}$ & $\begin{array}{c}\text { Fine/Coarse } \\
(\mathrm{F} / \mathrm{C})\end{array}$ \\
\hline$B^{\prime \prime}$ & 16 & 3.9 & 68 & 32 & 2.14 \\
\hline$B$ & 16 & 3.9 & 75 & 35 & 2.96 \\
\hline$B^{\prime}$ & 16 & 3.9 & 81 & 37 & 4.36 \\
\hline$B^{\prime \prime}$ & 31.5 & 4.9 & 40 & 31 & 0.68 \\
\hline$B$ & 31.5 & 4.9 & 48 & 33 & 0.94 \\
\hline$B^{\prime}$ & 31.5 & 4.9 & 56 & 35 & 1.27 \\
\hline
\end{tabular}

Testing procedure. Testing procedure worked on two stages. First, to determine the fresh properties of concrete mixtures, Slump and Ve-Be tests were performed. Test results were measured and recorded according to respectively the TS EN 12350-2 [2002] and the TS EN 12350-3 [2002] standard.

Hardened concrete tests were also performed on 28 day old concrete specimens. To determine mechanical properties, compressive, splitting tensile and flexural strengths were evaluated as recommended by respectively the TS EN 12390-3 [2010], the TS EN 12390-6 [2010] and the TS 10515 [1992] standards. $150 \times 150 \times 150 \mathrm{~mm}$ cube specimens were used for compressive strength and splitting tensile strength. 4point flexural strength test was performed on $150 \times 150 \times 500 \mathrm{~mm}$ prismatic beam specimens to determine flexural strength and toughness values. 


\section{RESULTS AND DISCUSSIONS}

Fresh concrete test results. Steel fibers tend to cluster due to decrease the flowability of the concrete, especially with coarse aggregates [ACI 544.1R 2005; Uygunoglu 2011]. Thus, conventional slump measurements are not effective to determine the workability of SFRC mixtures. Most SFRC applications need mechanical vibration for compaction. Thus, the Ve-Be test is highly recommended for assessing the workability of SFRC mixtures [Mehta and Monteiro 2006; ACI 544.1R 2005]. In this study, both tests were performed. Figure 2 provides the respective slump values for the mixtures. As been expected, the workability of the fresh mixtures remarkably decreases with the addition of steel fibers (figure 2).

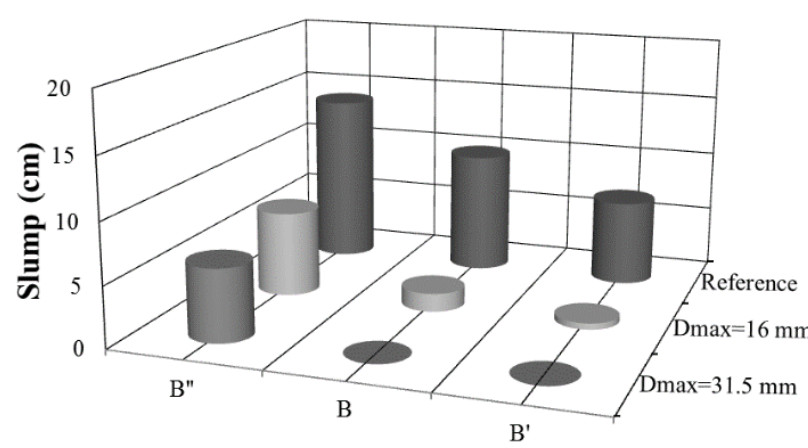

(a)

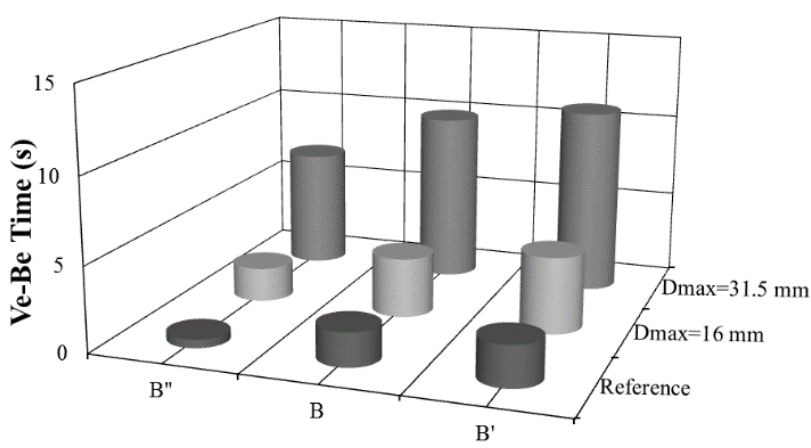

(b)

Figure 2. Fresh Concrete Test Results; (a) Slump, (b) Ve-Be test

Ve-Be tests were performed for all of the fresh mixtures. The Ve-Be times are also shown in figure 2. Because the Ve-Be time increases when the workability decreases, it is obvious that steel fiber addition causes to reduce the workability. Moreover, changing the fine-to-coarse aggregate ratio of the aggregate has an effect on the workability. As fine-to-coarse aggregate ratio increased, workability of the mixtures decreased from $B^{\prime \prime}$ to $B^{\prime}$. As explained before, as the amount of fine aggregate increases with the aggregate surface, lacking of mix water leads to decreased workability [Mehta and Monteiro 2006; Neville 1991; Alexander and Mindess 2005; Celik and Marar 1996]. Additionally, workability of SFRC mixtures especially with larger $D_{\max }$ is the lowest. It is known that concrete mixtures, with very coarse aggregates become harsh and unworkable. That is why it is recommended that $D_{\max }$ should be specified for the concrete mixtures and if the aggregates with larger $D_{\max }$ values are used, a lower volume fraction of steel fibers should be preferred [Mehta and Monteiro 2006; ACI 544.1R 2005].

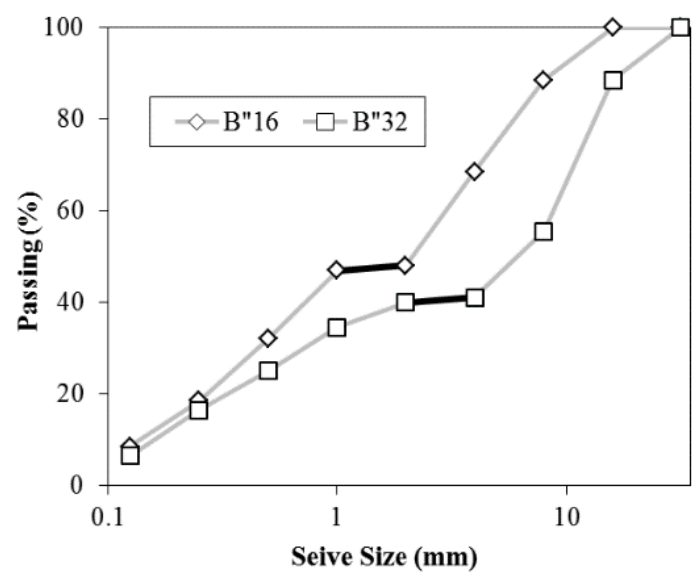

Figure 3. B" Grading Similarity to Gap-Grading 
The mixtures with $B^{\prime \prime}$ grading were the most workable mixtures (Figure 2). This could be why the $B^{\prime \prime}$ grading similar to a gap-graded aggregate (Figure 3). It is known that gap-graded aggregates lead to workable mixtures, despite the risk of segregation [Neville 1991].

\section{Hardened concrete test results}

Compressive strength. To observe the effect of changing aggregate gradations, figure $4 \mathrm{a}$ shows the compressive strength of the concrete specimens with different gradations from $B^{\prime \prime}$ to $B^{\prime}$. Fine aggregate ratio and $V_{\text {void }}$ influenced the compressive strength of both SFRC and plain concrete (reference), although the differences between compressive strength of SFRC and reference were not very large. Especially the $D_{\max }$ affected positively the compressive strength with a constant cement dosage and $W / C$ ratio (Figure 4a). It is known that the compressive strength of concrete increases with increasing $D_{\max }$ [Meddah et al. 2010; Ozbay 2010; Tumidajski and Gong 2006; Chenkui and Guofan 1995]. In addition, the effect of steel fibers on the compressive strength is negligible and [Mehta and Monteiro 2006; Altun et al. 2007; Olivito and Zuccarello 2010]. In fact, it can be seen in figure 4 a that fine-to-coarse aggregate ratio is more influential than adding $1 \%$ steel fibers on the compressive strength, especially with increasing $D_{\max }$.



(a)

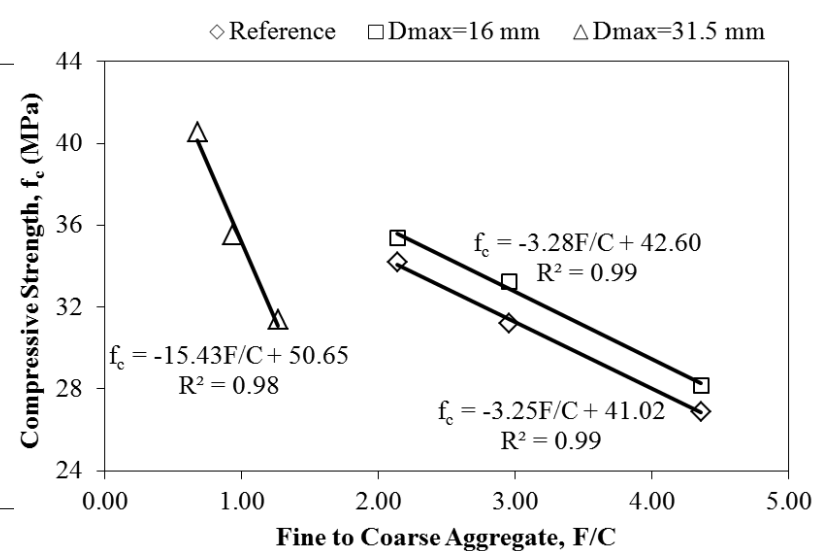

(b)

Figure 4. (a) Compressive Strengths of Specimens, (b) Relations between Fine-to-Coarse
Aggregate Ratio and Compressive Strength

The relations between fine-to-coarse aggregate ratio and compressive strength are given in figure $4 \mathrm{~b}$. In figure $4 \mathrm{~b}$, it can be seen the linear relations between $F / C$ and $f_{c}$. In figure $4 \mathrm{~b}$, the compressive strengths of both the SFRC and reference were reduced due to the increased $V_{\text {void }}$ (Table 2) although fine-to-coarse aggregate ratio increased. It is well known that unfilled voids by the cement paste reduce the mechanical strength of concrete, besides these voids can also increase for the unworkable mixture [Mehta and Monteiro 2006; Neville 1991]. Here, increased fine aggregate obviously was not enough to fill the $V_{\text {void. }}$ Thus, as the grading is changed from $B^{\prime \prime}$ to $B^{\prime}$, the compressive strength decreases due to the increased void content. In addition, when fine aggregate content increased, coarse aggregate content decreased to keep the total volume constant. Thus, surface of aggregate increased with constant a constant volume of cement paste.

The compressive strengths of specimens with highest $V_{\text {void }} B^{\prime}\left(\mathrm{f}_{\mathrm{c}}^{\mathrm{B} \prime}\right)$ were lower than specimens with the lowest $V_{\text {void }} B^{\prime \prime}\left(\mathrm{f}_{\mathrm{c}}^{\mathrm{B} \prime \prime}\right)$ (figure 4). Increasing rate of the compressive strength was $26 \%$ for $D_{\max }=16 \mathrm{~mm}$ and $29 \%$ for $D_{\max }=31.5 \mathrm{~mm}$ by changing the aggregate grading. Moreover, using larger $D_{\max }$ provided to increase almost $10 \%$ the compressive strength of SFRC. 
Splitting Tensile Strength. The changing of the splitting tensile strengths of the concrete specimens with different gradations from $B^{\prime \prime}$ to $B^{\prime}$ and the relations between fine-to-coarse aggregate ratio and splitting tensile strength have shown in respectively figure $5 \mathrm{a}$ and figure $5 \mathrm{~b}$. Fine-to-coarse aggregate ratio and $V_{\text {void }}$ also affected the splitting tensile strength for both SFRC and reference specimens. Placing steel fibers in plain concrete increases the tensile strength of the concrete because steel fibers improve ductility of concrete [Banthia and Sappakittipakorn 2007; Nataraja et al. 1999; Gopalaratnam and Gettu 1995; Chenkui and Guofan 1995; Topcu and Canbaz 2007]. As expected, the steel fibers remarkably improved the tensile strength of the concrete specimens, especially with larger $D_{\max }$ (figure 5a).

Because of the increased void content from $B^{\prime \prime}$ to $B^{\prime}$, the tensile strength decreased in figure 5a (Table 2). As explained previously, voids decrease the mechanical strength. Like the compressive strength, larger $D_{\max }$ had a positive effect on the tensile strength of SFRC with constant cement dosages and W/C ratios (figure $5 \mathrm{a})$. In figure $5 \mathrm{~b}$, it can also be seen the linear relations between $F / C$ and $f_{s t}$.

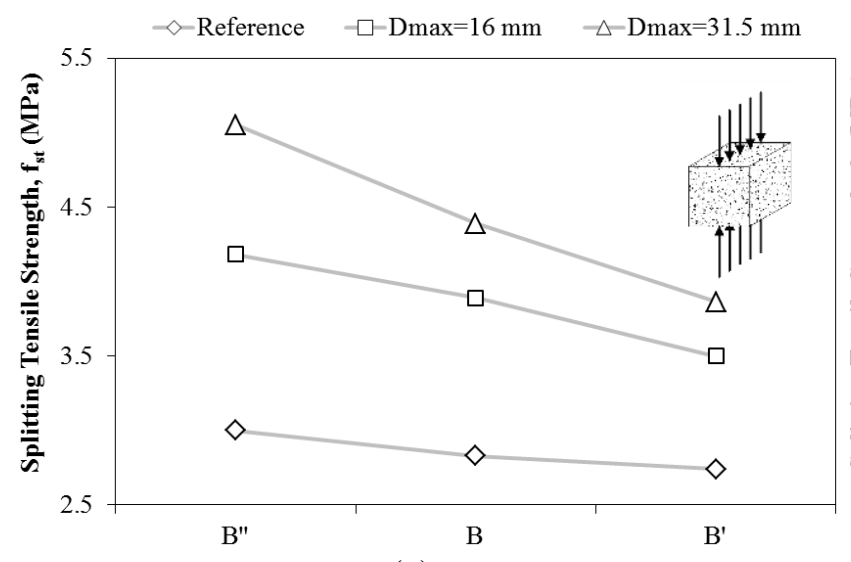

(a)



(b)

\section{Figure 5. (a) Splitting Tensile Strengths of Specimens, (b) Relations between Fine-to-Coarse Aggregate Ratio and Splitting Tensile Strength}

Flexural Strength. Figure $6 \mathrm{a}$ and $6 \mathrm{~b}$ gives the flexural strengths of the concrete specimens with different gradations from $B^{\prime \prime}$ to $B^{\prime}$ and the relations between fine-to-coarse aggregate ratio and flexural strength. The flexural strength values of specimens for constant cement dosages and $W / C$ ratios were influenced by fineto-coarse aggregate ratio, $D_{\max }$ and $V_{\text {void }}$ (figure 6a). As stated above, increased void content impacts the mechanical properties of concrete, negatively. It is also known that steel fibers have a significant improvement effect on the flexural strength like tensile strength [Banthia and Sappakittipakorn 2007; Nataraja et al. 1999; Gopalaratnam and Gettu 1995; Chenkui and Guofan 1995; Tadepalli et al. 2013; Topcu and Canbaz 2007]. In this study, the steel fibers improved the flexural strength of the concrete, especially with larger $D_{\max }$ (figure 6a).

Because of the increased void content from $B^{\prime \prime}$ to $B^{\prime}$, the flexural strength decreases (figure 6a) (Table 2). Moreover, the influence of $D_{\max }=31.5 \mathrm{~mm}$ on the flexural strength of SFRC was higher than $D_{\max }=16 \mathrm{~mm}$ similar to the compressive and splitting tensile strength (figure 6a). The flexural strength of SFRC can be enhanced by coarse aggregates with higher $D_{\max }$ values [Chenkui and Guofan 1995]. In figure 6b, it can be seen the linear relations between $F / C$ and $f_{\text {flex }}$.

Last of all, the specimens with the $B^{\prime \prime}$ gradation showed the highest mechanical performance for all strength values. By regression analysis, empirical relations given in the graphics can be written. It can be seen that there are strong correlations above $90 \%$ for proposed relations in this study (Figs. 4b, 5b, 6b). 


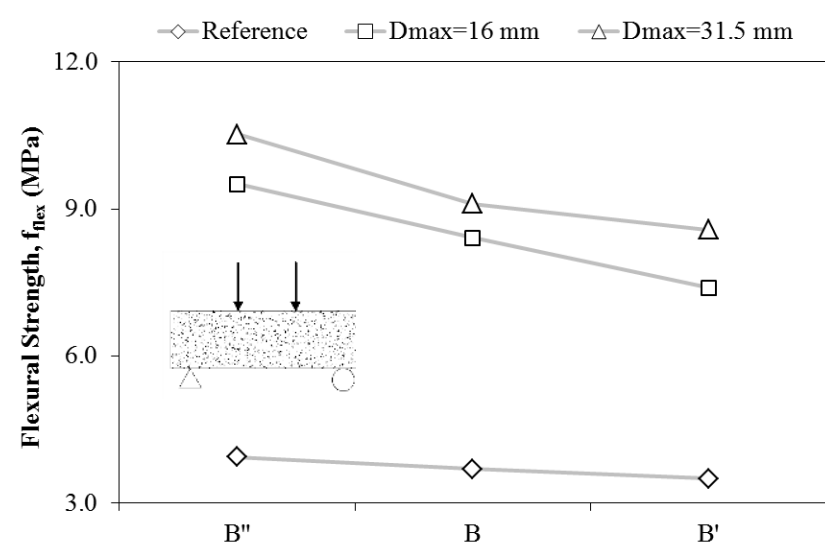

(a)



(b)

\section{Figure 6. (a) Flexural Strengths of Specimens, (b) Relations between Fine-to-Coarse Aggregate Ratios and Flexural Strength}

Toughness. Load and deflection values of beam specimens were recorded during the flexural strength test, and the load-deflection $(T-\delta)$ curves of SFRC specimens were obtained (figure 7). Unlike plain concrete, the SFRC can carry on remarkable loads even after the deflections considerably in excess of the fracture deflection of the plain concrete. Firstly, concrete matrix fails and then the failure occurs due to steel fibers completely pull-out or debonding. Steel fibers prone to transfer the stress to the concrete matrix by means of bond stresses occurred between fiber and concrete matrix. Thus, the SFRC does not fail suddenly after the first crack on contrary to plain concrete. The area under the load-deflection curve defined as the toughness $(T)$ value reflects the energy absorption of the [Tadepalli et al. 2013; Bentur and Mindess 2005; Shah 1984; Majdzadeh et al. 2006; Wang et al. 2011]. The toughness value of the SFRC is influenced by the concrete matrix properties. Aggregate grading and $D_{\max }$ slightly affects the toughness [Chenkui and Guofan 1995; Zhang et al. 2004].

For $B^{\prime \prime}, B$ and $B^{\prime}$ gradations, the $B^{\prime \prime}$ grading gave the best toughness performance for both $D_{\max }$ values (figure 8a). Figure 8a gives the toughness values of the SFRC specimens at $\delta=5 \mathrm{~mm} . D_{\max }=31.5 \mathrm{~mm}$ increased $10 \%$ toughness values at least. Considering the mechanical properties, these results for toughness are expected. In addition, linear relations between fine-to-coarse aggregate ratio and toughness values are written and given in figure $8 \mathrm{~b}$. There are also strong correlations above $90 \%$ for proposed relations for this study (figure $8 b$ ).

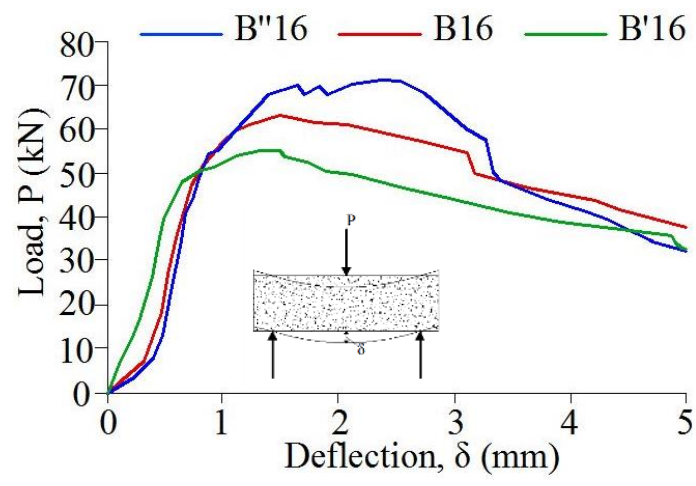

(a)

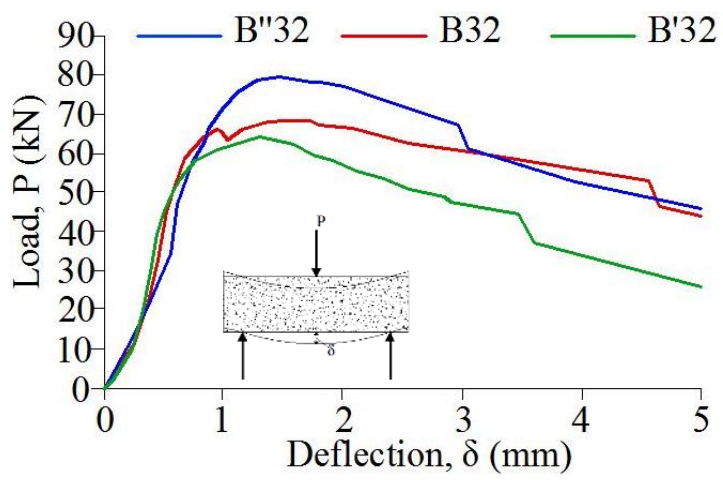

(b)

Figure 7. Load-Deflection Curves of SRFC Specimens (a) for $D_{\max }=16 \mathrm{~mm}$, (b) for $D_{\max }=31.5 \mathrm{~mm}$ 


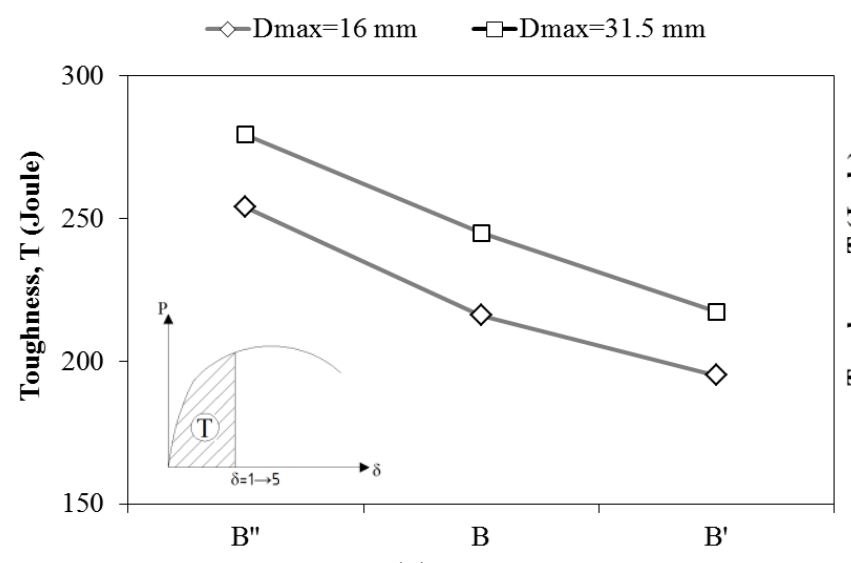

(a)

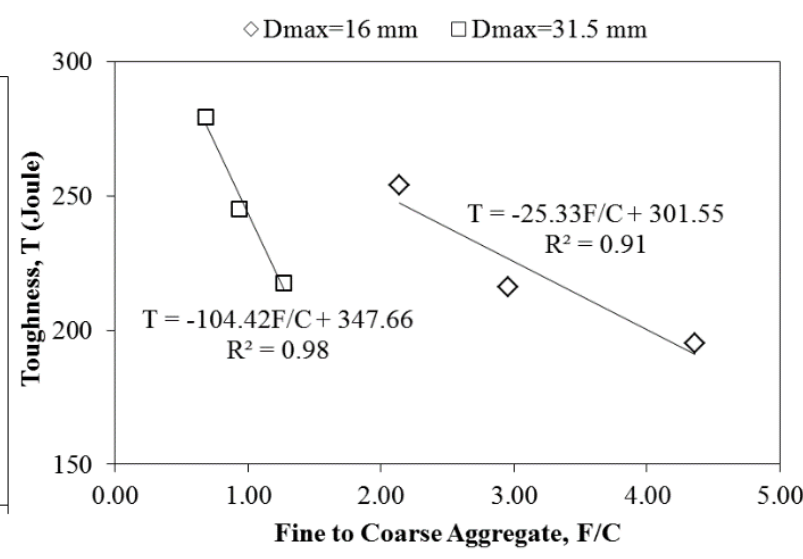

(b)

Figure 8. (a) Toughness of Specimens, (b) Relations between Fine-to-Coarse Aggregate Ratio and Toughness

\section{CONCLUSION}

Based on the experimental results on SFRC properties with constant cement dosages and $W / C$ ratios, the following conclusions can be reached in this study.

Firstly, using $1 \%$ steel fibers reduced the workability of the concrete noticeably. Changing the fine-tocoarse aggregate ratio had a significant effect on the workability of both SFRC and plain concrete. As fineto-coarse aggregate ratio increased, workability of the mixtures decreased. When the fineness modulus was kept constant, increasing fine aggregate content, which increased the surface area of the aggregates, decreased the workability for both $D_{\max }$ values. In addition, SFRC mixtures with larger $D_{\max }$ were the most unworkable mixtures in this study. For all of the SFRC mixtures, the $B^{\prime \prime}$ grading, which displayed gapgraded aggregates, was the most workable grading for both $D_{\max }$ values.

Mechanical properties such as the compressive strength, splitting tensile strength and flexural strength of the specimens were investigated experimentally. Although the compressive strengths of the reference and SFRC specimens were not very different, the splitting tensile strength and flexural strength were improved remarkably with steel fibers compared to the reference specimens. Moreover, using larger $D_{\max }$ improved mechanical test results of SFRC, significantly. All of the mechanical properties decreased from $B^{\prime \prime}$ to $B^{\prime}$ for both the reference and SFRC specimens for both $D_{\max }$ values. Furthermore, unfilled voids between the aggregate particles had a negative effect on the mechanical properties. In terms of toughness of the SFRC specimens, larger $D_{\max }$ increased the toughness of SFRC. The $B^{\prime \prime}$ grading showed the best toughness performance among the gradations for a constant fineness modulus $\left(B^{\prime \prime}, B\right.$ and $\left.B^{\prime}\right)$.

All given linear relations between all strength and toughness values and fine-to-coarse aggregate ratios had strong correlations above $90 \%$ in this study. Fine-to-coarse aggregate ratio of an aggregate gradation is an important parameter on concrete properties. Thus, it can be said that aggregates with different gradations shows different effects on SFRC properties even though having the same fineness modulus. Thus, the fineto-coarse aggregate ratio is another important parameter for a gradation curve. For the future studies, gradation curves may be defined with more parameters instead of with just one fineness modulus parameter. Last of all, it is possible to enhance or worsen both the workability and mechanical properties of SFRC by changing the fine-to-coarse aggregate ratio and $D_{\max }$ keeping constant fineness modulus of aggregate. 


\section{ACKNOWLEDGEMENT}

This research was supported by Firat University Scientific Research Projects Unit (Grant No. MF.13.02). In addition, authors acknowledge to Kemerli Firm (Turkey) for their material supports.

\section{REFERENCES}

ACI Committee 544, (2005). "State-of-the-art report on fiber reinforced concrete", ACI 544.1R-96 (Reapproved 2002), Manual of Concrete Practice 2005. American Concrete Institute, Michigan.

Alexander M, Mindess S. (2005). “Aggregates in concrete”. London: Taylor \& Francis Group.

Altun F, Haktanir T, Ari K. (2007). "Effects of steel fiber addition on mechanical properties of concrete and RC beams". Construction and Building Materials, 21(3), 654-661.

Banthia N. (1990). "A study of some factors affecting the fiber-matrix bond in steel fiber reinforced concrete". Canadian Journal of Civil Engineering, 17(4), 610-620.

Banthia N, Sappakittipakorn M. (2007). "Toughness enhancement in steel fiber reinforced concrete through fiber hybridization". Cement and Concrete Research, 37(9), 1366-1372.

Bentur A, Mindess S. (2005). "Fibre reinforced cementitious composites". New York: Elsevier Science Publishing.

Brandt AM. (2008). "Fibre reinforced cement-based (FRC) composites after over 40 years of development in building and civil engineering". Composite Structures, 86(1-3), 3-9.

Celik T, Marar K. (1996). "Effects of crushed stone dust on some properties of concrete". Cement and Concrete Research, 26(7), 1121-1130.

Cetin A, Carrasquillo RL. (1998). "High-performance concrete: influence of coarse aggregates on mechanical properties". ACI Materials Journal, 95(3), 252-61.

Chenkui H, Guofan Z. (1995). "Properties of steel fibre reinforced concrete containing larger coarse aggregate". Cement and Concrete Composites, 17(3), 199-206.

Gopalaratnam VS, Gettu R. (1995). "On the characterization of flexural toughness in fiber reinforced concretes". Cement and Concrete Composites, 17(3), 239-254.

Kim JJ, Kim DJ, Kang ST, Lee JH. (2012). "Influence of sand to coarse aggregate ratio on the interfacial bond strength of steel fibers in concrete for nuclear power plant". Nuclear Engineering Design, 252, 110 .

Majdzadeh F, Soleimani SM, Banthia N. (2006). "Shear strength of reinforced concrete beams with a fiber concrete matrix". Canadian Journal of Civil Engineering, 33(6), 726-734.

Meddah MS, Zitouni S, Belâabes S. (2010). "Effect of content and particle size distribution of coarse aggregate on the compressive strength of concrete". Construction and Building Materials, 24(4), 505512.

Mehta PK, Monteiro PJM. (2006). "Concrete: microstructure, properties and materials". 3th ed. New York: McGraw-Hill.

Nataraja MC, Dhang N, Gupta AP. (1999). "Stress-strain curves for steel-fiber reinforced concrete under compression". Cement and Concrete Composites, 21(5-6), 383-390. 
Neves RD, Fernandes de Almeida JCO. (2005). "Compressive behaviour of steel fibre reinforced concrete". Structural Concrete, 6(1), 1-8.

Neville AM. (1991). "Properties of concrete". 3th ed. London: Pitman.

Olivito RS, Zuccarello FA. (2010). "An experimental study on the tensile strength of steel fiber reinforced concrete". Composites Part B: Engineering, 41(3), 246-255.

Ozbay E. (2010). "Influence of aggregate size on the mechanical and transport properties of concretes and concrete-equivalent mortars". Canadian Journal of Civil Engineering, 37(10), 1303-1314.

Shah, SP. (1984). "Fiber reinforced concrete". In: Kong FK, Evans RH, Cohen E, Roll F, editors. Handbook of structural concrete, New York: McGraw-Hill.

Tadepalli PR, Mo YL, Hsu TTC. (2013). "Mechanical properties of steel fibre concrete". Magazine of Concrete Research, 65(8), $462-474$.

Topcu IB, Canbaz M. (2007). "Effect of different fibers on the mechanical properties of concrete containing fly ash". Construction and Building Materials, 21(7), 1486-1491.

TS 706 EN 12620 (2009). “Aggregates for concrete”. Turkish Standards Institutions, Ankara.

TS 802 (2009). "Design concrete mixes”. Turkish Standards Institutions, Ankara.

TS 10515 (1992). "Concrete-steel fibre reinforced-test method for flexural toughness". Turkish Standards Institutions, Ankara.

TS EN 197-1 (2005). “Cement. Part 1: compositions and conformity criteria for common cements”. Turkish Standards Institutions, Ankara.

TS EN 12350-2 (2002). "Testing fresh concrete - part 2: slump test". Turkish Standards Institutions, Ankara.

TS EN 12350-3 (2002). "Testing fresh concrete - part 3: vebe test". Turkish Standards Institutions, Ankara.

TS EN 12390-3 (2010). "Testing hardened concrete - Part 3 : Compressive strength of test specimens". Turkish Standards Institutions, Ankara.

TS EN 12390-6 (2010). "Testing hardened concrete - Part 6: Tensile splitting strength of test specimens”. Turkish Standards Institutions, Ankara.

Tumidajski PJ, Gong B. (2006). "Effect of coarse aggregate size on strength and workability of concrete". Canadian Journal of Civil Engineering, 33(2), 206-213.

Uygunoglu T. (2011). "Effect of fiber type and content on bleeding of steel fiber reinforced concrete". Construction and Building Materials, 25(2), 766-772.

Wang Z, Tang Y, Wang J. (2011). "Strength and toughness properties of steel fibre reinforced concrete under repetitive impact". Magazine of Concrete Research, 63(11), 883 -891.

Zhang MH, Li L, Paramasivam P. (2004). "Flexural toughness and impact resistance of steel-fibrereinforced lightweight concrete". Magazine of Concrete Research, 56(5), 251 -262. 